\title{
Ciência da Informação e humanidades digitais: mediações, agência e compartilhamento de saberes
}

\author{
Maria Aparecida Moura ${ }^{I}$ \\ https://orcid.org/0000-0003-2670-923X \\ I Universidade Federal de Minas Gerais, Belo Horizonte, MG, Brasil. \\ Doutora em Comunicação e Semiótica pela PUC/SP. \\ Professora titular da UFMG.
}

http://dx.doi.org/10.1590/1981-5344/3893

O artigo examina as interfaces entre a Ciência da Informação e as humanidades digitais. Para tanto, toma como referência a agenda de fenômenos infocomunicacionais enfrentados, as práticas de pesquisa e o tratamento das problemáticas éticas e sociais derivadas dos processos de intensificação da digitalização de dados e informações na sociedade contemporânea. Analisa as repercussões destas interfaces na agenda de pesquisas desenvolvidas no doutorado do Programa de Pósgraduação em Ciência da Informação da UFMG (PPGCI/UFMG) no período de 1997-2017.

Palavras-chave: Humanidades digitais. Ciência da Informação. Agência.

\section{Information science and digital humanities: mediations, agency and knowledge sharing}

This article examines the interfaces between Information Science and the digital humanities. To do so, it takes as reference the agenda of infocommunicational phenomena, the research practices and the treatment of the ethical and social problems derived from the processes of intensification of the digitalization of the information in 
contemporary society. It analyzes the repercussions of these interfaces on the research agenda developed in the $\mathrm{PhD}$ of the Graduate Program in Information Science at UFMG (PPGCI/ UFMG) in the period 1997-2017.

Keywords: Digital humanities. Information Science. Agency.

Recebido em 12.03.2019 Aceito em 12.03.2019

\section{Introdução}

A história de constituição da Ciência da Informação (CI) brasileira é marcada pelas preocupações com ideais desenvolvimentistas no âmbito da ciência e tecnologia nacional e pelo compromisso político com as mudanças sociais pela via da informação e do conhecimento. Por consequência, esses valores circunscreveram também a criação da pósgraduação, a pesquisa e o ensino superior na área.

Associada à revolução científica e técnica potencializada no contexto da segunda guerra mundial, a CI se viu às voltas, desde o seu nascedouro, com as questões relacionadas aos limites de suas fronteiras, aos efeitos dos atravessamentos tecnológicos, à definição de seu objeto e arcabouço teórico. Nesse sentido, Saracevic destacou que,

[...] três são as características gerais que constituem a razão da existência e da evolução da CI; outros campos compartilham-nas. Primeira, a CI é, por natureza, interdisciplinar, embora suas relações com outras disciplinas estejam mudando. A evolução interdisciplinar está longe de ser completada. Segunda, a CI está inexoravelmente ligada à tecnologia da informação. O imperativo tecnológico determina a $\mathrm{CI}$, como ocorre também em outros campos. Em sentido amplo, o imperativo tecnológico está impondo a transformação da sociedade moderna em sociedade da informação, era da informação ou sociedade pós-industrial. Terceira, a CI é, juntamente com muitas outras disciplinas, uma participante ativa e deliberada na evolução da sociedade da informação. A CI teve e tem um importante papel a desempenhar por sua forte dimensão social e humana, que ultrapassa a tecnologia. Essas três características ou razões constituem o modelo para compreensão do passado, presente e futuro da $\mathrm{CI}$ e dos problemas e questões que ela enfrenta. (SARACEVIC, 1996, p. 42)

De modo geral, é possível perceber que os dilemas derivados da tríade documento-suporte-arquivo estão na base dos estudos desenvolvidos na área. Além da constatação de que, ao longo de sua história, a área se ocupou intensamente em compreender e delinear suas fronteiras e especificidades. Contudo Gonzalez de Gomez (2017, p. 9) alerta para os riscos do "olhar organizador excludente" propiciado pela 
formação disciplinar e especialidades. Segundo a autora, "o cruzamento de fronteiras não implica necessariamente uma relação permanente ou duradoura entre duas áreas disciplinares em sua inteira extensão. As relações acontecem por vezes em alguns temas, incitadas por algumas questões, em circunstâncias específicas".

O contexto de consolidação das humanidades digitais tem propiciado à Ciência da Informação, em meio ao diálogo com outras áreas, se questionar sobre o estatuto contemporâneo do humanismo e sua episteme, conforme ressalta (CORMERAIS et al., 2016, p. 4). Os autores salientam a importância do estabelecimento de um processo de reflexividade distanciada nos processos digitais considerando-se, nesse ambiente as novas operações do saber contemporâneo.

Quadro 1 - As Ciências da Informação e Comunicação e a mutação da episteme

\begin{tabular}{c|c|c|c|c|c}
\cline { 2 - 6 } & Estudo & Transmissão & Valor & Crítica & Dispositivo \\
\hline \hline $\begin{array}{c}\text { Ciências da } \\
\text { natureza }\end{array}$ & experimentar/verificar & $\begin{array}{c}\text { Leis da } \\
\text { natureza }\end{array}$ & $\begin{array}{c}\text { Neutralidade } \\
\text { axiológica }\end{array}$ & $\begin{array}{c}\text { Crítica do } \\
\text { dogmatismo }\end{array}$ & $\begin{array}{c}\text { Ideal de } \\
\text { uma ciência } \\
\text { sem } \\
\text { dispositivos }\end{array}$ \\
\hline $\begin{array}{c}\text { Ciências } \\
\text { humanas }\end{array}$ & descrever/criticar & $\begin{array}{c}\text { Experiência } \\
\text { do mundo }\end{array}$ & $\begin{array}{c}\text { Regime de } \\
\text { engajamento }\end{array}$ & Crítica social & $\begin{array}{c}\text { Sociedade } \\
\text { sem } \\
\text { dispositivos }\end{array}$ \\
\hline $\begin{array}{c}\text { Ciências da } \\
\text { Informação } \\
\text { e } \\
\text { comunicação }\end{array}$ & modelizar/simular & $\begin{array}{c}\text { Modos de } \\
\text { existência } \\
\text { (humanas e } \\
\text { maquínicas) }\end{array}$ & $\begin{array}{c}\text { Praticabilidade } \\
\text { do saber }\end{array}$ & $\begin{array}{c}\text { Crítica } \\
\text { interdisciplinar } \\
\text { e } \\
\text { transdisciplinar }\end{array}$ & $\begin{array}{c}\text { Ciência e } \\
\text { sociedade } \\
\text { aparelhada }\end{array}$ \\
\hline
\end{tabular}

Fonte: CORMERAIS et al. (2016, p. 4).

Ao longo da história de constituição da Ciência da informação no contexto nacional e internacional nota-se um diálogo tenso e ainda não apaziguado envolvendo a imersão da área na economia de mercado, o acentuado binarismo das narrativas produzidas por uma espécie de imanência do tecnológico (ciberfetichismo) e uma dificuldade em integrar os "sentidos e experiências em relações que envolvem as alteridades culturais".

\section{Gonzalez de Gomez (2017, p. 1) enfatiza que,}

Os estudos da informação formam parte das mudanças das matrizes paradigmáticas das ciências contemporâneas. Mudanças que são consistentes com o deslocamento do conhecimento, da comunicação e da linguagem de seu locus investigativo prévio, no domínio reflexivo dos estudos filosóficos e humanísticos, conforme modos de olhar históricos, genealógicos ou interpretativos, para compor um domínio de construção de objetos ao que se aplicam metodologias explicativas, de concepção e modelização. Ao mesmo tempo, as tecnologias digitais vão compor o domínio investigativo das ciências humanas e sociais (como quando se pergunta pelas "humanidades 
digitais"), além de providenciar recursos procedimentais inovadores (como na e-ciencia e na ciência aberta e colaborativa). Em sua própria constituição, os estudos da informação surgem num cruzamento de fronteiras, e o entendimento dessa posição, na formação histórica das ciências e das técnicas, seria parte importante daquilo que será objeto de sua crítica e reflexão.

Conforme destacam Cormerais et al. (2016, p. 2) o papel da ciência da informação tem sido o de compreender (abordagem teórica), experimentar (abordagem prática), observar (abordagem teórica) e criar (abordagem pragmática) com os instrumentos do conhecimento.

No desempenho dessas diferentes abordagens, a CI, em sua história recente, tem desenvolvido experimentações que permeiam uma área de convergência e atividades científicas: as humanidades digitais.

As humanidades digitais constituem um território científico relativamente novo, decorrentes da interseção entre as Humanidades, as Ciências Sociais e as tecnologias digitais. Essa composição parece desafiar o modo contemporâneo de produzir ciência na medida em que a seara de produção, armazenamento e circulação do conhecimento está sobreposta em um mesmo ambiente digital.

Evidentemente, não se desconhece, nesse ambiente, o histórico da área em relação à abrangência e aos desdobramentos anunciados pelas humanidades digitais, visto que a análise das relações sociais atravessadas pelas mediações tecnológicas é um desafio constitutivo da CI.

Esse artigo examina as interfaces entre Ciência da Informação e Humanidades Digitais tomando como referência a agenda de fenômenos info-comunicacionais dinamicamente enfrentados, as práticas de pesquisa e o tratamento das problemáticas éticas e sociais derivadas dos processos de intensificação da digitalização da informação na sociedade contemporânea. Para tanto, analisam-se as repercussões destas interfaces nas pesquisas desenvolvidas no âmbito do doutorado em Ciência da Informação no Programa de Pós-graduação em Ciência da Informação (PPGCI/UFMG) no período de 1997 - 2017.

\section{Humanidades digitais: a pesquisa social em tempos liquidos e always on}

Precisamos buscar categorias de inteligibilidade 'conceitos quentes que derretam as fronteiras em que a ciência moderna dividiu e encerrou a realidade' (SANTOS, 2004, p. 72).

As humanidades digitais (HDs) são uma nova forma de se abordar as pesquisas em humanidades e ciências sociais, particularmente atravessadas pelo imperativo tecnológico.

Os referidos atravessamentos acontecem sob a égide de intensos fluxos de informação que permitem, em termos técnicos, a circulação de "significantes" livres da custódia dos "significados" (BAUMAN, 2012, p. 34), pela conectividade always on, "o fio invisível que se multiplica 
entrelaçando consciências, espaços, perguntas, desejos" (SANTAELLA; LEMOS, 2010, p. 55) em face do uso de tecnologias wireless e dispositivos móveis.

Atualmente, a constatação da complexidade para se identificar a autoridade epistêmica trouxe inúmeros desafios às diferentes áreas do conhecimento. A presença indiscriminada de atores humanos e agentes artificiais em ambientes hiperconectados exige a reconfiguração dos processos de produção do conhecimento e autoriza o surgimento da autoridade epistêmica distribuída. Nesses contextos, Gonzalez de Gomez (2017) destaca que os processos de validação e tomada de decisão são o "resultado da articulação de plurais saberes e vereditores". Isso se deve à constatação de que os agentes artificiais ultrapassaram em muito a simples competência de processamento simbólico e passaram a atuar como agentes semióticos em processos sígnicos.

A concepção de agência, presumida na autoridade epistêmica, é compreendida por Sewell Jr (1992) como a capacidade dos atores individuais ou coletivos transporem e estenderem regras e esquemas para novos contextos, através da interpretação e da mobilização de recursos culturais diferentes daqueles que constituíam a matriz. O autor percebe a

[...] agência como profundamente social ou coletiva. As transposições de esquemas e remobilizações de recursos que constituem agência são sempre atos de comunicação com outros. Agência implica uma capacidade de coordenar as ações de uma pessoa com os outros e contra os outros, para formar projetos coletivos, persuadir, coagir e monitorar os efeitos simultâneos das atividades pessoais e alheias. Além disso, a extensão da agência exercida por pessoas individuais depende profundamente em suas posições em organizações coletivas. (SEWELL JR, 1992, p. 21)

O campo de pesquisa em HDs se tornou possível devido à intensa digitalização de massas de dados (big data), à necessidade de compreensão da natureza dos dados obtidos, a ampliação de pesquisas colaborativas a distância e a alteração da cadeia de produção científica.

Conforme Kirschenbaum (2010, p. 56):

As humanidades digitais, também conhecidas como computação em humanidades, são um campo de estudo, pesquisa, ensino e invenção relacionado à interseção da computação e as disciplinas das ciências humanas. É metodológico por natureza e interdisciplinar em escopo. Envolve investigação, análise, síntese e apresentação de informações em formato eletrônico. Estuda como essas mídias afetam as disciplinas em que são usadas.

Em março de 2010, foi realizado em Paris o THATCamp 2010, ocasião em que foi elaborado o Manifesto das Humanidades digitais dirigido às comunidades de pesquisa e aos atores que integram os processos de criação, edição, valorização e conservação dos conhecimentos. 
De acordo com o manifesto as humanidades digitais "referem-se à transdisciplinaridade, que traz consigo métodos, dispositivos e heurísticas relacionadas ao digital no campo das ciências humanas e sociais".

O manifesto destaca os seguintes valores:

a) a constituição de uma comunidade de prática solidária, aberta, acolhedora e de livre acesso;

b) a formação de uma comunidade sem fronteiras, multilíngue e multidisciplinar;

c) foco no progresso do conhecimento, na qualidade da pesquisa nas diferentes disciplinas, e o enriquecimento do saber e do patrimônio coletivo;

d) a integração da cultura digital na definição da cultura geral do século XXI.

Conforme foi possível perceber no contexto de análise, a terminologia adotada e o diálogo transdisciplinar pretendido revelaram certa ambiguidade na definição e escopo das HDs. Embora o termo Digital Humanities em inglês não faça referência direta às Ciências sociais, da qual a Ciência da Informação é parte, tem havido um uso mais amplo do termo com inclusão de outros campos de conhecimento oriundos das humanidades e das Ciências sociais.

Dacos e Mounier (2015, p. 10) apontam que o primeiro período de adoção da informática nas pesquisas em humanidades caracterizou-se pelo uso de modelos quantitativos no desenvolvimento de análises estatísticas e recursos textuais.

Abiteboul e Hachez-Leroy (2015) afirmam que vivemos contemporaneamente uma transição nas humanidades demarcada pelo atravessamento tecnológico nas formas de se fazer ciência.

As humanidades digitais também são percebidas como uma metadisciplina que atua em uma zona de convergência e trocas transdisciplinares com foco nos esforços metodológicos de renovação nas humanidades e ciências sociais.

As HDs constituíram uma série de valores e métodos à medida de sua ampliação como comunidade de prática de proporções globais. Dentre os valores tacitamente pactuados, conforme aponta Honn (2014) está o caráter crítico e teórico da atuação humanista na análise de ferramentas, tecnologias e plataformas. A abordagem iterativa e experimental focaliza a experimentação e a assunção do risco como norma científica. A ênfase na produção colaborativa e distribuída permite 0 estabelecimento de colaborações sutis ou robustas entre diferentes atores. As produções multimodais e performativas potencializam os múltiplos modos de expressão do conhecimento. A orientação ao acesso aberto e acessível da produção científica tem como propósito ampliar as possibilidades de circulação do conhecimento produzido e a colaboração entre os pares. 
Os métodos emergentes organizados no âmbito dos projetos e experimentações em $\mathrm{HDs}^{1}$ tomam como referência o uso de tecnologias e a preocupação humanista. Dentre eles destacam-se: as curadorias críticas de dados, mídias digitais, coleções e narrativas acadêmicas; as publicações aumentadas baseadas em textualidades fluídas; descoberta e interpretação de grandes volumes de dados baseados em algoritmos, a análise digital de tendências, padrões e relacionamentos de grandes conjuntos de dados; análise cultural, agregação e mineração de dados; visualização e design de dados (relações estruturais, georreferenciamento e simulações); mídias locativas e mapeamento espesso (cultura digital e sistemas de informação geográfica - SIG); sistemas de arquivamento multimodais; produção distribuída de conhecimento e acesso performativo; jogos e narrativas interativas, codificação, software e estudos de plataformas; infraestruturas pervasivas e cultura remix.

Os dados digitais, transacionados no âmbito das HDs, são representativos e estratégicos apenas se sua cadeia de processamento (identificação, extração, integração, análise, publicação) permanecer próxima do trabalho dos atores sociais. Os métodos quali-quantitativos não nos permitem suavizar toda a complexidade da vida coletiva. A vantagem desses métodos é que eles são flexíveis o suficiente para seguir alguns fenômenos sociais ao longo de cada uma de suas dobras (VENTURINI; LATOUR, 2010, p. 7).

A realidade densa das humanidades digitais é fortemente condicionada pelo duplo papel exercido pelos softwares, como co-leitores e coautores. Conforme destaca Allen-Robertson (2017) o software é o coleitor e coautor ignorante das formas documentais digitais, introduzindo uma camada de complexidade muitas vezes negligenciada em nossa avaliação e interpretação de documentos digitais. Como co-leitor, AllenRobertson (2017) ressalta que os documentos digitais são mediados por muitas camadas de interpretação de software antes que se possa extrair qualquer elemento significativo deles. Nesse sentido, o documento digital é a confluência de sinais ordenados corretamente, camadas de operações de software, uma estrutura rígida de probabilidades codificadas como um formato de arquivo que contextualiza os dados.

Como coautor, o software não apenas medeia o nosso consumo, interpretação e geração de informações em documentos digitais, como também desempenha um papel fundamental na estruturação da autoria desses objetos. A materialidade de um meio e as técnicas de expressão que ele proporciona, colocarão limitações aos tipos de expressão e, portanto, aos tipos de geração de informação que realizam (ALLENROBERTSON, 2017, p. 9).

Nesse âmbito, o autor destaca que plataformas como o Twitter, o Youtube e o Facebook são espaços de propriedade privada que operam como guardiões da cultura contemporânea. No entanto, sua identificação como "plataformas" indica a multidão de papéis e prioridades que eles

${ }^{1}$ Disponível em: <https://web.archive.org/web/20150919224700/http://sites.northwestern.edu/guidetodh/valuesmethods/>. Acesso em: 21 nov. 2018. 
mantêm. O termo "plataforma" faz um trabalho discursivo crucial ao enquadrar o site como uma superfície politicamente neutra, em vez de reconhecer os muitos interesses concorrentes nos tipos de conteúdo que persistem e estão acessíveis (ALLEN-ROBERTSON, 2017, p. 11).

O duplo papel exercido pelos guardiões privados da cultura contemporânea, como mediadores e agentes, é, muitas vezes nocivo à definição de valor arquivístico, cultural e histórico, pois é cambiante e dependente das lógicas de mercado.

Nesse âmbito, é desafiadora a atuação dos internautas na web, visto que estes têm sido estimulados a produzir formas de arquivamento cada vez mais "complexas para localizar, analisar, conservar e interpretar" (CORMERAIS, 2016, p. 6).

No contexto de viabilidade das humanidades digitais em interface com a Ciência da Informação constituem desafio permanente o controle social dos processos de arquivamento da cultura contemporânea, o desenvolvimento de novas literacias que possam apoiar criticamente as lógicas interpretativas e os modelos formativos pactuados em tais ambientes.

\section{Humanidades digitais e os desafios para o campo da Ciência da Informação}

O que é bom é algo que vem da inovação. O bom não existe, como tal, num céu atemporal, com pessoas que seriam como Astrólogos do Bem, com a tarefa de determinar qual a natureza favorável das estrelas. O bom é definido por nós, é praticado e inventado. E esse é um trabalho coletivo. (FOUCAULT, 1988).

A ciência da informação se constitui em torno de três de questionamentos principais: a agenda de fenômenos info-comunicacionais enfrentados, as práticas de pesquisa e o tratamento das problemáticas éticas e sociais derivadas dos processos de intensificação da digitalização da informação dados na sociedade contemporânea (DOMENGET; BONACCORSI; CARAYOL, 2016).

Ao analisarmos a agenda de pesquisas desenvolvidas no âmbito da Ciência da Informação em face do caráter notadamente transdisciplinar das humanidades digitais constata-se uma sinergia de propósitos e um território comum de atuação.

Preocupações com as transformações dos saberes e competências, com as dimensões organizacionais dos projetos (atores, profissões e discurso) e com o caráter transdisciplinar da área estão frequentemente em evidência.

A observação das transformações da circulação do conhecimento e da comunicação digital está, portanto, no coração das Ciências da Informação e Comunicação, envolvendo não apenas a construção de marcos operacionais teóricos, mas também uma prática empírica de análise digital dos objetos e métodos analisados. Também deve ser acrescentado que as Ciências da Informação e Comunicação 'trabalham' na materialidade digital nos prismas esclarecedores de 
abordagens documentárias e informacionais, sócio-econômicos, interpretativos e semiológicos. (DOMENGET; BONACCORSI; CARAYOL, 2016, p. 1).

Do ponto de vista das mudanças nas práticas de pesquisa, nota-se uma preocupação sistemática com os conhecimentos produzidos a partir da experiência, as condições de produção, coleta e tratamento dos dados e com os impactos epistemológicos decorrentes da automação da pesquisa e do uso de algoritmos e Big Data.

Com relação aos aspectos éticos e sociais envolvidos na pesquisa em Ciência da Informação em interface com as HDs acentuam-se os esforços na efetivação de práticas participativas que tentam combinar uma perspectiva diacrônica na compreensão dos fenômenos.

O exame das interfaces entre a Ciência da Informação e as Humanidades Digitais revelou paralelismos, pontos de convergência e esforços cruzados. Buscou-se então examinar essas evidências ao longo dos primeiros 21 anos de desenvolvimento da formação em nível de doutorado do PPGCI/UFMG. Nesses, termos, buscou-se identificar nos estudos realizados pelos doutorandos do PPGCI evidências de dialogo.

O Doutorado do PPGCI/UFMG foi aprovado pela Capes e as instâncias institucionais da Universidade em julho de 1996, com início efetivo do curso no primeiro semestre de 1997.

Ao longo desses 21 anos foram realizadas cerca de 150 teses na área de concentração Produção, Organização e Utilização da Informação e a partir de 2017, na área de Informação, Cultura e Mediação.

A primeira tese defendida do PPGCI/UFMG, de autoria de Maria Beatriz Almeida Sathler Bretas, foi defendida em 24 de abril de 2000, sob o título "Interações telemáticas: estudo sobre jovens internautas de Belo Horizonte", O trabalho contou com a orientação acadêmica da Professora Ana Maria Pereira Cardoso. Em uma análise do conteúdo presente no resumo da referida tese, nota-se, desde o início, uma abertura do PPGCI em relação às humanidades digitais.

O estudo aborda processos comunicativos e demandas de informação, referentes a adolescentes de Belo Horizonte, usuários da Internet, com vistas a subsidiar políticas públicas na democratização das redes telemáticas. O trabalho, de natureza qualitativa, busca contribuições teórico-metodológicas em várias áreas do conhecimento, entre elas a da sociologia e a da história, na compreensão das interações sociais. Tendo o contexto como referência para a produção de sentido, são abordadas as transformações referentes às mudanças de paradigmas científicos; à transferência do espaço público para o campo mediático e à apresentação do quadro planetário de desenvolvimento humano, em que a Internet surge como fator paradoxal de inclusão e exclusão dos indivíduos. Assim, através do enfoque de problemas localizados na relação entre a escola e a tecnologia telemática, é discutida a necessidade de processos educativos que democratizem a produção cultural. O espaço virtual é examinado em analogia com o território urbano, identificando lugares de sociabilidade, para estabelecer 
parâmetros e categorias de classificação de lugares físicos e virtuais freqüentados pelos adolescentes 1 no cotidiano. O estudo enfoca, também, a retórica dos discursos eletrônicos na constituição de uma nova linguagem própria da Internet. A pesquisa empírica, que utilizou o recorte temporal de 1996 a 1999, foi constituída por dois momentos de aproximação da realidade; o primeiro compreendeu a busca, a coleta e a análise de 30 páginas pessoais de adolescentes de Belo Horizonte, na Internet, e o segundo momento envolveu a realização de grupos focais, presenciais, com a participação de 42 adolescentes, usuários da Internet, alunos de escolas de ensino fundamental e médio da cidade. A análise dos resultados, à luz do referencial teórico, identifica nos jovens um conhecimento tácito sobre a informática; as diferentes formas de apropriação da tecnologia pelo segmento observado e os objetivos de interação social presentes no uso da Internet, entre outras constatações. (BRETAS, 2000, p. 8).

Ao observar as demais teses desenvolvidas posteriormente, percebe-se o amadurecimento do diálogo da CI e as HDs com a explicitação de valores e metodologias compartilhadas presentes na agenda e práticas de pesquisas e a manutenção da preocupação com os aspectos éticos e sociais. Assim, temáticas como ensino a distância, sociedade da informação, governo eletrônico, ontologias, tratamento da linguagem natural, redes sociais, mobilidade, cognição situada, formação do leitor, memória, cultura digital, letramento informacional, informática em saúde, dentre outras sempre estiveram presentes nos esforços de produção e reflexão científica desenvolvidas no âmbito do PPGCI/UFMG.

Recentemente, em consonância com as tendências nacionais e internacionais, o PPGCI/UFMG deu início à implantação do Laboratório de Culturas e Humanidades Digitais (LabCult). O LabCult tem por objetivo fomentar "estudos teóricos, sistematizações, experimentações, produções e o desenvolvimento de métodos e técnicas de pesquisas aplicadas aos contextos digitais no âmbito da Ciência da Informação."

$\mathrm{Na}$ implantação do laboratório considerou-se que,

as possibilidades e os desafios representados pela Internet das coisas (IoT) e o Big Data na coleta, armazenamento, processamento e análise de grandes volumes de dados exigem que os estudos desenvolvidos no âmbito dos programas de pós-graduação possam, de algum modo, realizar experimentos e análises que preparem os pesquisadores para o enfrentamento das questões tecnológicas de nosso tempo de um ponto de vista crítico. (MOURA et al., 2017, p. 2)

Esse esforço de implementação e acompanhamento da agenda de pesquisa da área em âmbito nacional e internacional demonstra a capacidade de agência do PPGCI no enfrentamento das questões contemporâneas.

Nota-se, contudo, que os desafios e potencialidades examinados na interface entre a Ciência da Informação e Humanidades Digitais estão longe de uma estabilização possível, ou cenário conclusivo. Entretanto, a 
zona de convergência representada pelas humanidades digitais tende a potencializar os diálogos e a consolidação de uma perspectiva crítica acerca das transformações alcançadas.

\section{Conclusão}

O exame das interfaces entre a Ciência da Informação e as Humanidades Digitais revelaram potencialidades teórico-metodológicas e inúmeras conexões relacionadas aos valores, métodos científicos e a agenda de pesquisas.

As mudanças teóricas derivadas da compreensão ampla dos avanços digitais, a epistemologia dos dados proporcionada pela internet das Coisas (IoT), a análise social da estruturação de algoritmos e a gestão de Big data, a análise da economia discursiva na Internet, o aperfeiçoamento metodológico e a apreensão das dimensões sociais dos fenômenos em meio à superabundância de dados, interações sociais e o monitoramento tecnológico em tempo real reconfiguraram a área da Ciência da Informação na contemporaneidade.

O dinamismo, os cruzamentos teórico-metodológicos percebidos na interação entre as áreas analisadas reforçam a pertinência das recentes reformulações adotadas no âmbito do PPGCI/UFMG no limiar de seus 40 anos.

Constatou-se que as pesquisas desenvolvidas pelos doutorandos do PPGCI/UFMG, nos últimos 21 anos, evidenciaram a imprescindível sinergia, a sagacidade e o espírito crítico que devem presidir 0 enfrentamento científico das questões emergentes e históricas no âmbito da Ciência da Informação em nível nacional e internacional.

\section{Agradecimentos}

Agradecimentos são devidos ao Conselho Nacional de Desenvolvimento Científico e Tecnológico (CNPq), à Coordenação de Aperfeiçoamento de Pessoal de Nível Superior (CAPES) e à Fapemig/Fundação João Pinheiro, pelo apoio dado nas diferentes etapas do desenvolvimento deste trabalho.

\section{Referências}

ABITEBOUL, S.; HACHEZ-LEROY, F. Humanités numériques. Encyclopédie de I'humanisme méditerranéen, 2015. 15 p. Disponível em $<$ https://hal.inria.fr/hal-01120259/file/HumanitesNumeriques.022015.pdf>. Acesso em: 21 dez. 2018.

ALLEN-ROBERTSON, J. Critically assessing digital documents: materiality and the interpretative role of software. Information, Communication \& Society, v. 21, n. 11, p. 1732-1746, 2017. Available: $<$ http://repository.essex.ac.uk/20094/1/Critically\%20assessing\%20digital $\% 20$ documents $\% 20$ materiality $\% 20$ and $\% 20$ the $\% 20$ interpre $>$. Acesso em: 21dez. 2018. 
BAUMAN, Z. Ensaios sobre o conceito de cultura. Rio de Janeiro: Jorge Zahar, 2012.

BAUMAN, Z. Modernidade líquida. Rio de Janeiro: Jorge Zahar, 2001.

BRETAS, M. B. A. S. Interações telemáticas: estudo sobre jovens internautas de Belo Horizonte. Belo Horizonte: Escola de Ciência da Informação, 2000.

CORMERAIS, F. et al. Les SIC à l'épreuve du digital et des Humanités : des origines, des concepts, des méthodes et des outils. Revue française des sciences de l'information et de la communication, n. 8, 2016.

Disponível em: <http://journals.openedition.org/rfsic/1820>. Acesso em: 21 dez. 2018.

DACOS, M.; MOUNIER, P. Humanités numériques: état des lieux et positionnement de la recherche française dans le contexte international. Paris: OpenEdition, 2015. Disponível em:

$<$ https://www.enssib.fr/bibliotheque-numerique/documents/65357humanites-numeriques-etat-des-lieux-et-positionnement-de-la-recherchefrancaise-dans-le-contexte-international.pdf>. Acesso em: 21 dez. 2018.

DOMENGET, J.- C. ; BONACCORSI, J.; CARAYOL, V. Introduction au dossier "Humanités numériques et SIC". Revue française des sciences de I'information et de la communication, n. 8, 29 mars 2016. Disponível em: < http://journals.openedition.org/rfsic/1984>. Consulté le: 2 juin 2018.

FOUCAULT, M. Power, moral values, and the intellectual: an interview with Michael Foucault conducted by Michael Bess. History of present, v. 4, n. 1/2, p. 11-13. Disponível em: <https://www.michaelbess.org/foucaultinterview/>. Acesso em: 21dez. 2018.

GIDDENS, A. The constitution of society: outline of the theory of structuration. Berkeley and Los Angeles: University of California Press, 1984.

GONZALEZ DE GOMEZ, M. N. A Ciência da Informação no cruzamento de fronteiras. In: ENCONTRO DA ASSOCIAÇÃO DE EDUCAÇÃO E PESQUISA EM CIÊNCIA DA INFORMAÇÃO DA IBERO-AMÉRICA E CARIBE (EDICIC), 10., Belo Horizonte, 2016. Anais... Belo Horizonte: ECI/UFMG, 2017. p. 35-61.

HONN, J. A guide to digital humanities: values \& methods. 2014.

Disponível em:

<https://web.archive.org/web/20150919224700/http://sites.northwester

n.edu/guidetodh/values-methods/>. Acesso em: 4 jun. 2018.

KIRSCHENBAUM, M. G. What is digital humanities and what's it doing in english departments? ADE Bulletin, v. 150, n. 7, p. 55-61, 2010.

Disponível em:

<https://www.ade.mla.org/content/download/7914/225677>. Acesso em: 1 jun.2018. 
MOURA, M. A. et al. Projeto do laboratório de culturas e humanidades digitais. Belo Horizonte: PPGCI, 2017. [s.n.t].

RENDUELES, C. Sociofobia: mudança política na era da utopia digital. São Paulo: Edições Sesc, 2016.

SANTAELLA, L.; LEMOS, R. Redes digitais: a cognição conectiva do Twitter. São Paulo: Paulus, 2010.

SANTOS, B. de S. Um discurso sobre as ciências. São Paulo: Cortez, 2004.

SARACEVIC, T. Ciência da Informação; origens, evolução e relações.

Perspectivas em Ciência da Informação, v. 1, n. 1, p. 41-62, 1996.

SEWELL Jr., W. H. A theory of structure: duality, agency, and transformation. American Journal of Sociology, v. 98, n. 1, p. 1-29, Jul. 1992. Disponível em:

<http://www.ir.rochelleterman.com/sites/default/files/sewell\%201992.pdf $>$. Acesso em: 6 jun. 2018.

VENTURINI, T.; LATOUR, B. The social fabric: digital traces and qualiquantitative methods'. In: CAP DIGITAL. Proceedings of future en seine 2009: the digital future of the city. Paris: Ed. Cap Digital, 2010. p. 87-101. 
Ciência da Informação e humanidades digitais: mediações,

Maria Aparecida Moura agência e compartilhamento de saberes 